\title{
Predictors of technical difficulty with duodenal ESD
}

\section{다)(우우}

\author{
Authors \\ Motohiko Kato ${ }^{1,2}$, Motoki Sasaki ${ }^{2}$, Mari Mizutani ${ }^{1}$, Koshiro Tsutsumi ${ }^{2}$, Yoshiyuki Kiguchi ${ }^{2}$, Teppei Akimoto ${ }^{2}$, Makoto \\ Mutaguchi ${ }^{1}$, Atsushi Nakayama², Kaoru Takabayashi ${ }^{3}$, Ai Fujimoto², Yasutoshi Ochiai², Tadateru Maehata², Takanori \\ Kanai ${ }^{1}$, Naohisa Yahagi ${ }^{2}$
}

Institutions

1 Division of Gastroenterology and Hepatology, Department of Internal Medicine, Keio University School of Medicine, Tokyo, Japan

2 Division of Research and Development for Minimally Invasive Treatment, Cancer Center, Keio University School of Medicine, Tokyo, Japan

3 Center for Diagnostic and Therapeutic Endoscopy, Keio University School of Medicine, Tokyo, Japan

submitted 24.4.2019

accepted after revision 17.6.2019

Bibliography

DOI https://doi.org/10.1055/a-0967-4744 |

Endoscopy International Open 2019; 07: E1755-E1760

(c) Georg Thieme Verlag KG Stuttgart · New York eISSN 2196-9736

Corresponding author

Motohiko Kato, MD, PhD, Division of Gastroenterology and Hepatology, Department of Internal Medicine, Keio

University School of Medicine, 35, Shinanomachi, Shinjuku-

ku, Tokyo 160-8582, Japan

Fax: +81-3-3353-6247

motohikokato@keio.jp

\section{ABSTRACT}

Background and study aims Duodenal endoscopic submucosal dissection (ESD) is still considered technically challenging; however, few studies have objectively analyzed predictors of the technical difficulty. Therefore, the aim of the current study was to elucidate predictors of the technical difficulty of duodenal ESD.

Patients and methods This was a retrospective observational study. From June 2010 to June 2017, a total of 174 consecutive patients with superficial duodenal epithelial neoplasia who underwent ESD were included in this study. We tried to identify predictors for technical difficulty of ESD by defining technical difficulty as either procedure time $>100$ minutes or intraprocedural perforation. Moreover, we constructed a scoring system consisting of factors that were significant in the multivariate analysis.

Results The proportion of patients with technical difficulty was $34.5 \%$. In the multivariate analysis, lesion location in flexural part [odds ratio (OR), 2.61; $95 \%$ confidence interval (CI), $1.02-6.68$ ], larger lesion size $(>40 \mathrm{~mm})(\mathrm{OR}, 5.26$; $95 \% \mathrm{Cl}, 2.15-12.9)$, and occupied circumference $>50 \%$ of the duodenum (OR, $5.80 ; 95 \% \mathrm{Cl}, 1.83-18.4)$ were associated with technical difficulty.

Conclusion A lesion location in flexural part, lesion size $>40 \mathrm{~mm}$ and occupied circumference $>50 \%$ were risk factors for technical difficulty of duodenal ESD.

\section{Introduction}

Superficial duodenal epithelial neoplasia (SDET) was previously considered a rare disease [1-4]; estimated prevalence rates of $0.02 \%$ to $0.5 \%$ have been reported in autopsy series [5-7]. However, the ability to detect SDET has been increasing with recent advances in endoscopic technologies [8]. Due to the rarity of SDET, there are no established guidelines for treatment of SDET except for ampullary tumors [9].

Endoscopic mucosal resection (EMR) is a simple procedure but sometimes fails in piecemeal resection and is related to $20 \%$ to $30 \%$ of local recurrence after piecemeal EMR [10-12]. Alternatively, ESD achieves secure en bloc resection even in larger lesions [13-17]. Recently we reported that ESD achieved more than $90 \%$ of en bloc resection even in lesions larger than $20 \mathrm{~mm}$ [17]. On the other hand, previous studies reported that duodenal ESD is associated with more complications such as perforation and bleeding [17-25]. In particular, $13 \%$ to $50 \%$ incidence of perforation is reported in previous studies [17, $19,20,22-25]$. Duodenal ESD is more effective as a secure local treatment but considered technically challenging.

If we can predict technical difficulty of ESD, it would have clinical impact in that we could better prepare according to technical difficulty for each patient. For example, we could choose general anesthesia in the operating room for cases in which technical difficulty is expected or conscious sedation in the endoscopy unit for cases anticipated to be easier. In other organs, such as the stomach and colorectum, some clinical fea- 
tures of the lesion such as location and size would predict technical difficulty [26, 27]. However, to date, few studies have objectively analyzed predictors of technical difficulty of duodenal ESD. Therefore, the aim of the current study was to elucidate predictors of technical difficulty of duodenal ESD.

\section{Patients and methods}

\section{Study design and patient eligibility}

This was a retrospective observational study. From June 2010 to June 2017, a total of 174 consecutive patients with SDET who underwent resection with ESD at our institute were included. There was a case of intraoperative perforation requiring conversion to surgery, and that case was excluded from data analysis. This study was performed in accordance with the 2008 revision of the Helsinki Declaration. This is an accompanying research study [17], and patient consent was obtained in the original research study. The study protocol was approved by the institutional review board (20150221).

\section{ESD procedure}

In our institute, duodenal ESD is performed under either conscious sedation consisting of benzodiazepine, pethidine, and dexmedetomidine or general anesthesia with intratracheal intubation. The latter is applied for challenging cases (for example, lesions exceeding $40 \mathrm{~mm}$ or with poor scope maneuverability). ESD procedures were performed by six expert endoscopists who had performed more than 1,000 ESD procedures and at least 200 in each organ (esophagus, stomach, and colorectum) at the beginning of this study. ESD procedures were performed principally using a therapeutic endoscope with a water jet function (GIF- Q260 J, Olympus Medical Systems, Tokyo, Japan). This endoscope has a $9.8-\mathrm{mm}$ outer diameter, 3.2-mm working channel, and $210^{\circ}$ upward angle.

A tapered tip hood was put on the tip of the endoscope to facilitate to enter narrow submucosal space (ST Hood Fujifilm Corp, Tokyo, Japan). Generally, a submucosal injection of $10 \%$ glycerine solution (Glyceol Chugai Pharmaceutical Co., Ltd, Tokyo, Japan) with epinephrine (dilution 1:400,000) was administered. In difficult cases, $0.4 \%$ sodium hyaluronate (Mucoup, Boston Scientific Japan, Tokyo, Japan) was used as needed. A mucosal incision was made or submucosal dissection was performed using a DualKnife or a DualKnife J with a length of 1.5 mm (Olympus Medical Systems, Tokyo, Japan). A HooKknife (Olympus Medical Systems, Tokyo, Japan) was used in difficult cases, such as in cases with poor scope maneuverability. Minor bleeding was treated with these devices by placing the tip of the device into the outer sheath; however, in cases of spurting bleeding, hemostatic forceps (Coagrasper, Olympus Medical Systems, Tokyo, Japan) were used. These energy devices were powered by a high-frequency electrosurgical unit (VIO 300 D, ERBE Elektromedizin, Tübingen, Germany) with dry cut (effect 3-30W) for mucosal incision, swift coagulation (effect 4$30 \mathrm{~W}$ ) for submucosal dissection, and soft coagulation (effect 5-50W) for hemostasis.
- Table 1 Clinical characteristics of the analyzed cases.

\begin{tabular}{|c|c|c|}
\hline Age & Mean \pm SEM & $62.8 \pm 0.91$ \\
\hline Sex & Female & $67 \%$ \\
\hline \multirow[t]{5}{*}{ Location } & Bulbs & $14 \%$ \\
\hline & Superior duodenal angle & $9 \%$ \\
\hline & Descending part & $66 \%$ \\
\hline & Inferior duodenal angle & $8 \%$ \\
\hline & Transverse part & $3 \%$ \\
\hline \multirow[t]{4}{*}{ Site } & Anterior wall & $15 \%$ \\
\hline & Lateral wall & $20 \%$ \\
\hline & Posterior wall & $33 \%$ \\
\hline & Medial wall & $32 \%$ \\
\hline Lesion size & Mean \pm SEM, mm & $27.4 \pm 0.96$ \\
\hline \multirow{2}{*}{$\begin{array}{l}\text { Occupied circumfer- } \\
\text { ence }\end{array}$} & $>1 / 2$ & $92 \%$ \\
\hline & $<1 / 2$ & $8 \%$ \\
\hline \multirow[t]{3}{*}{ Macroscopic type } & $0-1$ & $7 \%$ \\
\hline & $0-11 a$ & $77 \%$ \\
\hline & 0 -IIc & $16 \%$ \\
\hline
\end{tabular}

\section{Post-ESD management}

Patients were fasted for 2 days, including the day of the ESD procedure, and received intravenous hydration. After evaluating results of blood examinations and abdominal X-rays, the patients were allowed to drink on postoperative Day (POD) 2 . The patients were allowed to begin a liquid diet on POD 3 and were generally discharged on POD 5. The timing of permitting patients to drink and eat did not differ even in cases of perforation unless there were no symptoms. We did not use prophylactic antibiotics routinely. Patients took proton pump inhibitors (rabeprazole $20 \mathrm{mg} /$ day, lansoprazole $30 \mathrm{mg} /$ day, or esomeprazole $20 \mathrm{mg} /$ day) for 3 weeks after ESD.

\section{Measured outcomes}

We collected information on procedure time and intraprocedural perforation rate as data associated with the technical difficulty of duodenal ESD. In this study, we defined patients with technical difficulty as patients with either a prolonged procedure time or intraprocedural perforation. We defined prolonged procedure time as procedure time exceeding the procedure time of the first quartile.

\section{Statistical analysis}

In this study, we performed logistic regression analysis to identify risk factors for technical difficulty, intraprocedural perforation, and prolonged procedure time. Longitudinal lesion location (duodenal flexure including the supraduodenal angle (SDA) or inferior duodenal angle [IDA] vs. other locations), site (posterior wall vs. others), lesion size $(-39 \mathrm{~mm}$ vs. $\geq 40 \mathrm{~mm})$, and occupied circumference (less than half vs. more than half 


\begin{tabular}{|c|c|c|c|c|c|c|c|}
\hline \multirow{2}{*}{\multicolumn{3}{|c|}{ Procedure time }} & \multicolumn{3}{|c|}{ Median [range], min } & \multicolumn{2}{|c|}{$50[10-360]$} \\
\hline & & & \multicolumn{3}{|c|}{$>100 \min , \mathrm{n}(\%)$} & \multicolumn{2}{|l|}{$46(26.6 \%)$} \\
\hline \multicolumn{3}{|c|}{ Resection in a single piece } & \multicolumn{3}{|c|}{ Possible, n (\%) } & \multicolumn{2}{|l|}{$170(97.7 \%)$} \\
\hline \multicolumn{3}{|l|}{ R0 resection } & \multicolumn{3}{|c|}{ Possible, n (\%) } & \multicolumn{2}{|l|}{$147(84.4 \%)$} \\
\hline \multicolumn{3}{|l|}{ Perforation } & \multicolumn{3}{|c|}{ Present, n (\%) } & \multicolumn{2}{|l|}{$22(12.7 \%)$} \\
\hline \multicolumn{3}{|l|}{ Bleeding } & \multicolumn{3}{|c|}{ Present, n (\%) } & \multicolumn{2}{|l|}{$164(5.2 \%)$} \\
\hline \multicolumn{3}{|c|}{ Cases with technical difficulty } & \multicolumn{3}{|c|}{ Present, n (\%) } & \multicolumn{2}{|l|}{$60(34.5 \%)$} \\
\hline \multicolumn{8}{|c|}{ Table 3 Predictors of technical difficulty. } \\
\hline \multirow{2}{*}{\multicolumn{2}{|c|}{ Variable }} & \multicolumn{3}{|l|}{ Univariate } & \multicolumn{3}{|l|}{ Multivariate } \\
\hline & & Odds ratio & $95 \% \mathrm{Cl}$ & $P$ value & Odds ratio & $95 \% \mathrm{Cl}$ & $P$ value \\
\hline \multirow[t]{2}{*}{ Location } & Duodenal flexure (SDA/IDA) & 2.83 & $1.25-6.37$ & $0.012^{1}$ & 2.61 & $1.02-6.68$ & $0.047^{1}$ \\
\hline & Others & 1 & & & 1 & & \\
\hline \multirow[t]{2}{*}{ Site } & Posterior wall & 1.49 & $0.75-2.96$ & 0.26 & 0.94 & $0.42-2.11$ & 0.89 \\
\hline & Others & 1 & & & 1 & & \\
\hline \multirow[t]{2}{*}{ Lesion size } & $>40 \mathrm{~mm}$ & 1.08 & $0.86-1.53$ & $<0.01^{1}$ & 5.26 & $2.15-12.9$ & $<0.01^{1}$ \\
\hline & $\leq 39 \mathrm{~mm}$ & 1 & & & 1 & & \\
\hline Occupied & More than $1 / 2$ & 12.6 & $4.47-35.7$ & $<0.01^{1}$ & 5.80 & $1.83-18.4$ & $<0.01^{1}$ \\
\hline circumference & Less than $1 / 2$ & 1 & & & 1 & & \\
\hline $\begin{array}{l}\text { SDA, supraduode } \\
{ }^{1} \text { Statistically sign }\end{array}$ & $\begin{array}{l}\text { angle; IDA, inferior duodenal angl } \\
\text { int }\end{array}$ & & & & & & \\
\hline
\end{tabular}

the duodenum) were selected as influencing factors. Statistical analysis was performed using JMP software (ver. 13.0.0, SAS Institute, Inc., Cary, North Carolina, United States), and a $P<0.05$ was considered statistically significant.

\section{Results}

\section{Patient characteristics}

Characteristics of patients included in the study are described in $>$ Table 1. Approximately $20 \%$ of lesions were located in the duodenal flexure. Mean lesion size was $27.4 \pm 0.96 \mathrm{~mm}$. More than $90 \%$ of lesions occupied a circumference of less than one-half the duodenum. There were three cases of local residual recurrence after previous treatment.

\section{Clinical outcomes of duodenal ESD}

Clinical outcomes of duodenal ESD are shown in $>$ Table 2. Resection in a single piece and $\mathrm{R} 0$ resection rate were performed in $97.7 \%$ and $84.4 \%$ of cases, respectively. In one case, conversion to laparoscopic partial duodenectomy was required due to massive bleeding and perforation caused by poor maneuverability of endoscope. Median procedure time was 50 minutes and $26.6 \%$ of patients had a procedure time longer than 100 minutes, which was the first quartile of the procedure time. Intraprocedural perforation occurred in $12.7 \%$ of the included patients. Thus, $34.5 \%$ of patients had technical difficulties during duodenal ESD.

\section{Predictors for difficult ESD, intraprocedural perforation, and prolonged procedure time}

We performed logistic regression analysis to determine predictors for difficult ESD, intraprocedural perforation, and prolonged procedure time. In univariate analysis, lesion location in the duodenal flexure, larger lesion size, and an occupied circumference of more than half the duodenum were associated with a significant increase in technical difficulty of duodenal ESD, while lesion location in the posterior wall was associated with significant decrease in technical difficulty of ESD. In multivariate analysis, lesion location in the duodenal flexure (OR, 2.61; 95\% confidence interval [CI], 1.02-6.68), larger lesion size (OR, 5.26; $95 \% \mathrm{Cl}, 2.15$-12.9), and an occupied circumference of more than half the duodenum (OR, 5.80; $95 \% \mathrm{Cl}, 1.83$ 18.4) were associated with a significant increase in technical difficulty ( $\triangleright$ Table 3$)$.

Larger lesion size and an occupied circumference of more than half the duodenum were significantly associated with intraprocedural perforation in univariate analysis, while only larger lesion size was significantly associated with intraprocedural perforation (OR, 3.84; $95 \% \mathrm{Cl}, 1.22-12.1)$ in multivariate analysis ( $\triangleright$ Table 4$)$. 
- Table 4 Predictors of intraprocedural perforation.

\begin{tabular}{|c|c|c|c|c|c|c|c|}
\hline \multicolumn{2}{|l|}{ Variable } & \multicolumn{3}{|l|}{ Univariate } & \multicolumn{3}{|c|}{ Multivariate } \\
\hline & & Odds ratio & $95 \% \mathrm{Cl}$ & $P$ value & Odds ratio & $95 \% \mathrm{Cl}$ & $P$ value \\
\hline \multirow[t]{2}{*}{ Location } & Duodenal flexure (SDA/IDA) & 1.56 & \multirow[t]{2}{*}{$0.52-4.62$} & \multirow[t]{2}{*}{0.44} & 1.06 & \multirow[t]{2}{*}{$0.31-3.59$} & \multirow[t]{2}{*}{0.93} \\
\hline & Others & 1 & & & 1 & & \\
\hline \multirow[t]{2}{*}{ Site } & Posterior wall & 1.58 & \multirow[t]{2}{*}{$0.63-3.96$} & \multirow[t]{2}{*}{0.33} & 2.38 & \multirow[t]{2}{*}{$0.85-6.66$} & \multirow[t]{2}{*}{0.10} \\
\hline & Others & 1 & & & 1 & & \\
\hline \multirow[t]{2}{*}{ Size of lesion } & $>40 \mathrm{~mm}$ & 5.04 & \multirow[t]{2}{*}{$1.99-12.8$} & \multirow[t]{2}{*}{$<0.01^{1}$} & 3.84 & \multirow[t]{2}{*}{$1.22-12.1$} & \multirow[t]{2}{*}{$0.022^{1}$} \\
\hline & $\leq 39 \mathrm{~mm}$ & 1 & & & 1 & & \\
\hline \multirow[t]{2}{*}{ Occupied circumference } & More than $1 / 2$ & 5.12 & \multirow[t]{2}{*}{$1.92-13.7$} & \multirow[t]{2}{*}{$<0.01^{1}$} & 2.70 & \multirow[t]{2}{*}{$0.81-8.95$} & \multirow[t]{2}{*}{0.10} \\
\hline & Less than $1 / 2$ & 1 & & & 1 & & \\
\hline
\end{tabular}

- Table 5 Predictors of prolonged procedure time.

\begin{tabular}{|c|c|c|c|c|c|c|c|}
\hline \multicolumn{2}{|l|}{ Variable } & \multicolumn{3}{|l|}{ Univariate } & \multicolumn{3}{|c|}{ Multivariate } \\
\hline & & Odds ratio & $95 \% \mathrm{Cl}$ & $P$ value & Odds ratio & $95 \% \mathrm{Cl}$ & $P$ value \\
\hline \multirow[t]{2}{*}{ Location } & Flexural part (SDA/IDA) & 3.27 & \multirow[t]{2}{*}{$1.43-7.47$} & \multirow[t]{2}{*}{$<0.01^{1}$} & 3.31 & \multirow[t]{2}{*}{$1.21-9.07$} & \multirow[t]{2}{*}{$0.020^{1}$} \\
\hline & Others & 1 & & & 1 & & \\
\hline \multirow[t]{2}{*}{ Site } & Posterior wall & 0.43 & \multirow[t]{2}{*}{$0.19-0.97$} & \multirow[t]{2}{*}{$0.032^{1}$} & 2.00 & \multirow[t]{2}{*}{$0.72-5.52$} & \multirow[t]{2}{*}{0.18} \\
\hline & Others & 1 & & & 1 & & \\
\hline \multirow[t]{2}{*}{ Lesion size } & $>40 \mathrm{~mm}$ & 11.5 & \multirow[t]{2}{*}{$5.11-25.7$} & \multirow[t]{2}{*}{$<0.01^{1}$} & 5.59 & \multirow[t]{2}{*}{$2.20-14.2$} & \multirow[t]{2}{*}{$<0.01^{1}$} \\
\hline & $\geq 39 \mathrm{~mm}$ & 1 & & & 1 & & \\
\hline \multirow[t]{2}{*}{ Occupied circumference } & More than $1 / 2$ & 16.9 & \multirow[t]{2}{*}{$6.20-46.2$} & \multirow[t]{2}{*}{$<0.01^{1}$} & 7.83 & \multirow[t]{2}{*}{$2.52-24.3$} & \multirow[t]{2}{*}{$<0.01^{1}$} \\
\hline & Less than $1 / 2$ & 1 & & & 1 & & \\
\hline
\end{tabular}

Lesion location in the duodenal flexure, larger lesion size, and occupied circumference of more than half the duodenum were associated with a significant increase in technical difficulty of ESD in terms of prolonged procedure time, while lesion location in the posterior wall was associated with a significant decrease in technical difficulty of ESD in univariate analysis. In multivariate analysis, lesion location in the duodenal flexural (OR, 3.31; $95 \% \mathrm{Cl}, 1.21-9.07$ ), larger lesion size (OR, 5.59; $95 \% \mathrm{Cl}, 2.20-14.2)$, and an occupied circumference of more than half the duodenum (OR, 7.83; $95 \% \mathrm{Cl}, 2.52-24.3$ ) were associated with a significant increase in technical difficulty ( Table 5).

\section{Discussion}

In this retrospective study, we tried to find predictors of technical difficulty of duodenal ESD through analysis of outcomes of duodenal ESD in 174 consecutive patients. Longitudinal lesion location in the duodenal flexure, lesion size larger than $40 \mathrm{~mm}$, and an occupied circumference of more than half the duodenum were significantly associated with technical difficulty. In terms of intraprocedural perforation, larger lesion size was the only predictor, and for prolonged procedure time, longitudinal lesion location in the duodenal flexure, lesion size larger than $40 \mathrm{~mm}$, and an occupied circumference of more than half the duodenum were independent predictors.

Advances in endoscopic devices and accumulation of knowledge of management of complications and technical tips for ESD have contributed to widespread of ESD especially in Japan. Many studies have revealed favorable outcomes of ESD with low morbidity rates, favorable $\mathrm{R} 0$ resection rates, and high organ preservation rates for lesions in the esophagus, stomach, and colorectum $[14,15,28]$. Thus, ESD for superficial esophageal, gastric, or colorectal epithelial lesions is a standard treatment in Japan. Indeed, more than $50 \%$ of early gastric cancers are 
treated by ESD, and esophageal, gastric, and colorectal ESD have been approved by healthcare insurance.

On the other hand, duodenal ESD has been considered to be very high risk, with a $13 \%$ to $50 \%$ incidence of perforation in previous studies [19,20,22-25]. This high complication rate reflects the technical difficulty of duodenal ESD. In fact, the duodenum, especially the distal part, is very far from the mouth so that the maneuverability of the endoscope is often limited, and sometimes it is quite difficult to even approach the lesion. Due to the narrow space of the submucosal layer, it is difficult to go beneath the lesion. Burner's glands and vessels are rich in the submucosal layer; therefore, visualization tends to be poor while dissecting this layer. Most importantly, the wall of the duodenum is extremely thin; therefore, perforation occurs easily [29].

As mentioned above, duodenal ESD is technically difficult; however, recent advances in devices and endoscopic techniques have contributed to improvement in outcomes. Recently, we reported a novel ESD technique, the "water pressure method," which utilizes a pressure jet of water through a transparent hood with a small-caliber tip to open a narrow space in the submucosa after initial mucosal incision and submucosal dissection [30]. The pocket creation method (PCM) is also a novel endoscopic technique proposed by Miura and Yamamoto. In this method, a submucosal pocket is created at the beginning without extending the mucosal incision; as a result, stable conditions and good submucosal visualization can be obtained [31]. And a traction-assisted ESD technique has been reported $[32,33]$. Using these modified endoscopic treatments, outcomes of duodenal ESD have improved. In fact, in the latest report about short-term outcomes of duodenal ESD [17], the perforation rate was $15.5 \%$, and this is one of the lowest incidences despite the large sample size of the study.

With improvement in outcomes, duodenal ESD is expected to become used more widely; therefore, it is important to identify features of difficult lesions. Here, we found that longitudinal lesion location in the duodenal flexure, lesion size larger than $40 \mathrm{~mm}$, and occupied circumference of more than half the duodenum were predictors of technical difficulty. It is reasonable that the proportion of difficult ESD procedures increased with increasing lesion size. In addition, our results suggest that there are two possible reasons for technical difficulty. In lesions located in the duodenal flexure, maneuverability of the endoscope tends to be poor. Furthermore, it is difficult to adjust device direction in situations in which lesions occupy a large circumference within the duodenum because the working channel of the endoscope is commonly located at the 6- to 7o'clock position, making it difficult to almost impossible to access the lesion when the lesion is located in the opposite direction.

Our study has several limitations, mainly due to its singlecentered retrospective study design. First, all procedures were performed by expert endoscopists at a high-volume center, and the results are difficult to generalize. Second, we could not eliminate a certain degree of selection bias, although we only included consecutive patients. Third, we could not analyze subjective factors associated with technical difficulty, such as the psychological stress of the operator. Due to these limitations, the results of our study should be interpreted carefully.

\section{Conclusion}

In conclusion, the current study revealed that longitudinal lesion location in the duodenal flexure, lesion size larger than $40 \mathrm{~mm}$, and occupied circumference of more than half the duodenum were significantly associated with technical difficulty of duodenal ESD. These findings would be helpful for risk stratification and management of patients undergoing duodenal ESD.

\section{Competing interests}

None

\section{References}

[1] Murray MA, Zimmerman MJ, Ee HC. Sporadic duodenal adenoma is associated with colorectal neoplasia. Gut 2004; 53: 261 - 265

[2] Burgerman A, Baggenstoss AH, Cain JC. Primary malignant neoplasms of the duodenum, exclusing the papilla of vater; a clinicopathologic study of 31 cases. Gastroenterology 1956; 30: $421-431$

[3] Barclay TH, Kent HP. Primary carcinoma of the duodenum. Gastroenterology 1956; 30: $432-446$

[4] Arai T, Murata T, Sawabe M et al. Primary adenocarcinoma of the duodenum in the elderly: clinicopathological and immunohistochemical study of 17 cases. Pathol Int 1999; 49: $23-29$

[5] Fischer HP, Zhou H. Pathogenesis of carcinoma of the papilla of Vater. J Hepatobiliary Pancreat Surg 2004; 11: $301-309$

[6] Kim HK, Lo SK. Endoscopic approach to the patient with benign or malignant ampullary lesions. Gastrointestinal endoscopy clinics of North America 2013; 23: 347-383

[7] Kakushima N, Kanemoto H, Tanaka M et al. Treatment for superficial non-ampullary duodenal epithelial tumors. World J Gastroenterol 2014; 20: $12501-12508$

[8] Goda K, Kikuchi D, Yamamoto Y et al. Endoscopic diagnosis of superficial non-ampullary duodenal epithelial tumors in Japan: Multicenter case series. Dig Endosc 2014; 26: (Suppl. 02): $23-29$

[9] ASGE Standards of Practice Committee. Chathadi KV, Khashab MA et al. The role of endoscopy in ampullary and duodenal adenomas. Gastrointest Endosc 2015; 82: $773-781$

[10] Horiki N, Omata F, Uemura M et al. Risk for local recurrence of early gastric cancer treated with piecemeal endoscopic mucosal resection during a 10-year follow-up period. Surg Endosc 2012; 26: 72 - 78

[11] Katada C, Muto M, Manabe T et al. Local recurrence of squamous-cell carcinoma of the esophagus after EMR. Gastrointest Endosc 2005; 61: $219-225$

[12] Sakamoto T, Matsuda T, Otake Y et al. Predictive factors of local recurrence after endoscopic piecemeal mucosal resection. J Gastroenterol 2012; 47: 635-640

[13] Kato M, Nishida T, Hamasaki T et al. Outcomes of ESD for patients with early gastric cancer and comorbid liver cirrhosis: a propensity score analysis. Surg Endosc 2015; 29: 1560 - 1566

[14] Kato M, Nishida T, Yamamoto K et al. Scheduled endoscopic surveillance controls secondary cancer after curative endoscopic resection for early gastric cancer: a multicentre retrospective cohort study by Osaka University ESD study group. Gut 2013; 62: 1425-1432 
[15] Tsujii Y, Nishida T, Nishiyama O et al. Clinical outcomes of endoscopic submucosal dissection for superficial esophageal neoplasms: a multicenter retrospective cohort study. Endoscopy 2015; 47: 775 - 783

[16] Kato M, Nishida T, Tsutsui S et al. Endoscopic submucosal dissection as a treatment for gastric noninvasive neoplasia: a multicenter study by Osaka University ESD Study Group. J Gastroenterol 2011; 46: 325 331

[17] Yahagi N, Kato M, Ocihai Y et al. Outcomes of endoscopic resection for superficial duodenal epithelial neoplasia. Gastrointest Endosc 2018; 88: 676-682

[18] Hoteya S, Furuhata T, Takahito T et al. Endoscopic submucosal dissection and endoscopic mucosal resection for non-ampullary superficial duodenal tumor. Digestion 2017; 95: 36 -42

[19] Honda T, Yamamoto H, Osawa H et al. Endoscopic submucosal dissection for superficial duodenal neoplasms. Dig Endosc 2009; 21: $270-274$

[20] Takahashi T, Ando T, Kabeshima Y et al. Borderline cases between benignancy and malignancy of the duodenum diagnosed successfully by endoscopic submucosal dissection. Scand J Gastroenterol 2009; 44: $1377-1383$

[21] Endo M, Abiko Y, Oana S et al. Usefulness of endoscopic treatment for duodenal adenoma. Dig Endosc 2010; 22: 360-365

[22] Jung JH, Choi KD, Ahn JY et al. Endoscopic submucosal dissection for sessile, nonampullary duodenal adenomas. Endoscopy 2013; 45: $133-135$

[23] Matsumoto S, Miyatani H, Yoshida Y. Endoscopic submucosal dissection for duodenal tumors: a single-center experience. Endoscopy 2013; 45: $136-137$

[24] Kakushima N. Hurdles of duodenal endoscopic submucosal dissection, delayed bleeding and perforation. Dig Endosc 2015; 27: 298 299
[25] Nonaka S, Oda I, Tada K et al. Clinical outcome of endoscopic resection for nonampullary duodenal tumors. Endoscopy 2015; 47: $129-$ 135

[26] Imagawa A, Okada H, Kawahara Y et al. Endoscopic submucosal dissection for early gastric cancer: results and degrees of technical difficulty as well as success. Endoscopy 2006; 38: 987 - 990

[27] Hori K, Uraoka T, Harada K et al. Predictive factors for technically difficult endoscopic submucosal dissection in the colorectum. Endoscopy 2014; 46: $862-870$

[28] Saito Y, Uraoka T, Yamaguchi Y et al. A prospective, multicenter study of 1111 colorectal endoscopic submucosal dissections (with video). Gastrointest Endosc 2010; 72: 1217-1225

[29] Kato M, Yahagi N. Advanced endoscopic treatment of gastric and duodenal neoplasms: beyond standard EMR and ESD. Am J Gastroenterol 2018; 113: $1423-1426$

[30] Yahagi N, Nishizawa T, Sasaki M et al. Water pressure method for duodenal endoscopic submucosal dissection. Endoscopy 2017; 49: E227-E228

[31] Miura Y, Shinozaki S, Hayashi Y et al. Duodenal endoscopic submucosal dissection is feasible using the pocket-creation method. Endoscopy 2017; 49: 8-14

[32] Tashima T, Nonaka K, Kurumi H et al. Successful traction-assisted endoscopic submucosal dissection using dental floss and a clip for a huge superficial nonampullary duodenal epithelial tumor with severe fibrosis (with video). JGH Open 2019; 3: 179-181

[33] Goda Y, Mori H, Kobara H et al. Efficacy of sufficient operation view by ring-shaped thread counter traction for safer duodenal ESD. Minim Invasive Ther Allied Technol 2018; 27: 327-332 